\title{
An Algorithm to Predict Accurate Output Power of a Glass-Glass (Semitransparent) Solar Thermal Module Using Artificial Neural Network
}

\author{
Ruby Beniwal ${ }^{\# 1}$, G.N. Tiwari*2and H.O. Gupta ${ }^{\# 3}$ \\ \#Department of Electronics \& Communication Engineering, \\ Jaypee Institute of Information Technology, Noida, India \\ ${ }^{1}$ ruby.beniwal@gmail.com, ruby.beniwal@jiit.ac.in \\ ${ }^{3}$ hariomgupt@gmail.com \\ *Indian Institute of Technology Delhi, India
}

\begin{abstract}
This paper presents an algorithm to predict output power or performance parameters i.e., open circuit voltage and short circuit current of a glass-glass (G-G)i.e., semitransparentsolar thermal module very close to the experimental values. The predicted performance parameters by the proposed algorithm have been found closer to the experimental values or actual parameters than those computed by the artificial neural network (ANN) and analytical approach alone.The proposed algorithm uses ANN to reduce the root mean square error (RMSE)upto $100 \%$ between performance parameters of the prototype solar cell model under study due to ANN and analytical approaches alone. Solar irradiation andsolar-cell temperature are the essential parameters for design, prediction and performance analysis of any photovoltaic solar energy system. Therefore, solar irradiation,and solar cell temperature have been taken as input parameters in the proposed algorithm, ANN model and analytical model.
\end{abstract}

Keywords: ANN;glass-glass photovoltaic solar cell;RMSE

\section{INTRODUCTION}

Solar power in India is a fast developing industry with a capacity of 8,062 MW (8GW) as of 31July 2016.This is the best option for utilization of non-conventional energy sources. Photovoltaic thermal system (i.e. PVT module) is found to be a good choice for getting maximum electrical output power because thermal energy and electrical energy are considered simultaneously in it. The performance of PVT module depends upon several factors such as solar irradiation, ambient temperature, solar cell temperature, area of solar cell, wind, weather and climate conditions, etc. [1] have been noticed that measurement of solar irradiation from all location is difficult. Also, installation and maintenance cost of these measuring devices are too high. [2] and [3] have been reported few algebraic models of PV solar cells to predict their generated energy and performance parameters, but these models need input parameters like solar irradiation, solar cell temperature, etc. which are normally hard to access for all locations and all weather conditions .

Some researchers has been explained Greek long-term energy consumption prediction using artificial neural networks [4].[5] have been compared regression analysis, decision tree and neural networks to predict electricity energy consumption. Artificial neural networks for the prediction of the energy consumption of a passive solar building have been designed by [6] .[7]have been applied artificial neural network (ANN) method to energy analysis of thermodynamic systems. [8] have been analyzed performance of Solar Collectors Using artificial neural networks. [9] have been improved the performance of model for photovoltaic array.[10] have been evaluated cloudiness, haziness factor for Composite Climate. [11] have been analyzed energy and exergy of a hybrid photovoltaic thermal double pass air collector. They have also been analyzed performance of a hybrid photovoltaic thermal double pass air collector using ANN [12]. Literature suggests artificial neural network as a good approach to estimate the performance parameters of a system.

Authors have discussed the advantages of ANN like as simplified mathematical model, easy to learn new functional dependencies and new patterns. [13] have been designed fuzzy logic controller for photovoltaic simulator.[14] have been applied genetic algorithm with multi-objective function to improve the efficiency of glazed photovoltaic thermal system for New Delhi(India) climatic condition. [15] have been derived an analytical expression of temperature dependent electrical efficiency of N-PVT water collectors connected in series.[16] have been proposed a methodology to estimate the power generation of invisible solar photovoltaic sites.

[8]have been reported ANN with 10 neurons in hidden layer to predict the performance parameters of solar collector installed at a location in Beijing with very low error in comparison to the experimental values. They considered all performance parameters as training data in input layer and observed a good agreement between 
experimental values and results from ANN model. But, authors have noticed difference in between both the results from experimental and ANN model, if compared on the basis of RMSE. Sufficient research work has not been reported in the literature on the comparison of the results obtained from two or more approaches by taking RMSE into account and minimizing it. Therefore, in this paper attempt has been done by the authors to develop an algorithm to reduce RMSE using ANN to predict the performance parameters very close to the experimental values for all weather conditions. Here, authors have considered output power or generated maximum power as performance parameter.

\section{DESCRIPTIONOF PHOTOVOLTAIC THERMAL SOLAR CELL MODEL UNDER STUDY}

Photovoltaic solar cell converts solar energy into heat and electricity. Thephotovoltaic solar cell can be modeledas a five parameter photovoltaic analytical or electrical model. The photovoltaic solar cell can also be modeled as an ANN model.Both the models are discussed in following sections:

\section{A. Five Parameter Photovoltaic Analytical or Electrical Model:}

Behavior of a photovoltaic solar cell is explicit and nonlinear. It can be represented by current-voltage (I-V) characteristics and mathematical models described by [9]. A five parameters photovoltaic model under study is shown in fig.1 [9] below.

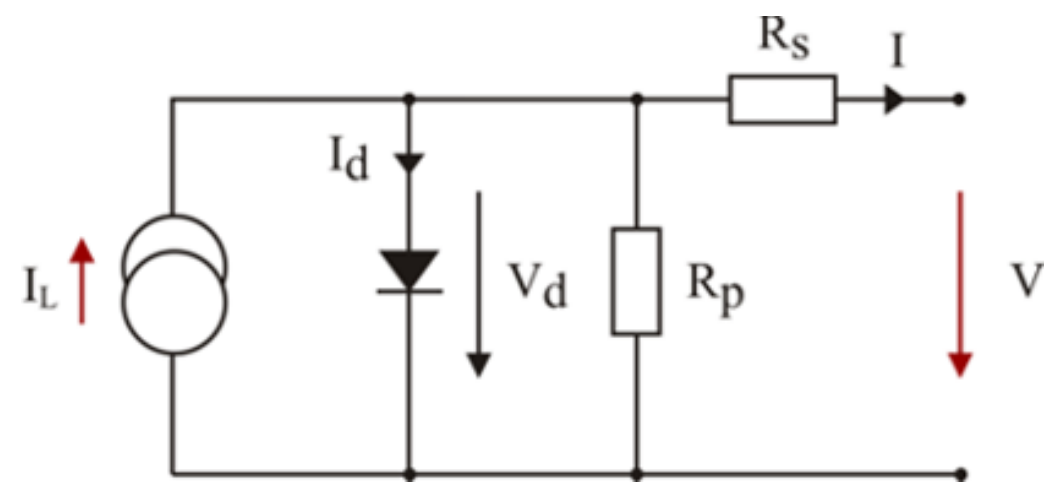

Fig.1:Five parameter photovoltaic analytical or electrical model

Thefive parameter photovoltaic analytical or electrical model can be expressed by voltage current characteristic equation as follows:

$$
I=I_{L}-I_{S}\left[\exp \left(\frac{q\left(V+I R_{S}\right)}{K T_{C} A}-1\right]-\left(V+I R_{S}\right) / R_{P}\right.
$$

Where, $I_{L}$ is photocurrent,

$I_{S}$ is solar cell saturation current,

$q$ is an electron charge, $\mathrm{K}$ is Boltzmann's constant,

$T_{C}$ is Photovoltaic cell working temperature,

$A$ is an ideal factor,

$R_{P}$ is a parallel resistanceand

$R_{S}$ is series resistance.

Photocurrent $I_{L}$ depends on solar irradiation $S$ and ambient temperature $T_{C}$ that can be expressed by following equation

$$
I_{L}=\left[I_{S C}+K_{I}\left(T_{c}-T_{r e f}\right)\right] S
$$

where $I_{S C}$ is photovoltaic cell short circuit current at $25^{\circ} \mathrm{C}$ and $1 \mathrm{KW} / \mathrm{m}^{2}$

$K_{I}$ is constant,

$S$ is solar irradiation and

$T_{r e f}$ is reference temperature.

For an ideal Photovoltaic cell, series resistance will be zero and parallel resistance will be infinite. So, Simplified equation for calculation of current $I$ is

$$
I=I_{L}-I_{S}\left[\exp \left(\frac{q V}{K T_{C} A}\right)-1\right]
$$

and at $I=0$, open circuit voltage is

$$
V_{O C}=\frac{K T_{C} A}{q} \ln \left(\frac{I_{L}}{I_{S}}+1\right)
$$


The fill factor or curve factor (FF) is a measurement of the I-V curve sharpness.It is related with output power and efficiency $\eta$. The relation can be defined as follows:

$$
\eta_{C}=\frac{P_{\max }}{P_{\text {in }}}=\frac{F F \times I_{S C} \times V_{O C}}{S \times \text { Area }}=\frac{I_{\max } \times V_{\max }}{S \times \text { Area }}
$$

Literature shows that the PV module solar cell efficiency is temperature dependent. The PV module solar cell temperature is inversely related with PV module solar cell efficiency i.e. with increase in cell temperature, PV module solar cell efficiency will decrease and output power will also decrease because output power is proportionally related with efficiency. In literature two type PV module solar cell are mentioned i.e. opaque (Glass to tedlar) and semitransparent (glass to glass).

\section{B. Thermal Model:}

PVT module extract electrical energy using external circuit and thermal energy using heat transfer method. In heat transfer method, losses (upwardand back) have importance to obtain energy balance equation for unit area of PVT module.

If $\tau$ is transmissivity of glass, $\alpha$ is fraction of radiation incident $I_{T}$ on surface of PVT module, $\eta_{c}$ is the conversion efficiency of PVT module, $U_{L}$ is loss coefficient, $T_{C}$ is solar cell temperature and $T_{a}$ is ambient temperature. Then Energy Balance Equation can be explained as follows:

$$
\left[\tau \alpha I_{T}\right]=\left[\eta_{C} I_{T}+U_{L}\left(T_{C}-T_{a}\right)\right]
$$

with $\eta_{c}=0,\left[\tau \alpha / U_{L}\right]$ can be established as constant to calculate solar cell temperature $T_{C}$.

Using this $T_{C}$, electrical efficiency $\eta_{e l}$ can be calculated by:

$$
\eta_{\mathrm{el}}=\eta_{0}\left[1-\beta_{0}\left(\mathrm{~T}_{\mathrm{C}}-298\right)\right]
$$

where $_{0}$ is PVT module efficiency at $298{ }^{\circ} \mathrm{K}$ temperature and $\beta_{0}$ is silicon efficiency temperature coefficient $\left(4.5 \times 10^{-3} \mathrm{~K}^{-1}\right)$.

[14] have been described the thermal model of N-PVT water collectors connected in series. With some assumptions as mentioned in literature two type PV module energy balance equations can be determined:

i) For Opaque PV module:The opaque PV module can be modeled mathematically as follows:

$$
\tau_{g}\left[\alpha_{c} \beta_{c} I(t)+\left(1-\beta_{c}\right) \alpha_{T} I(t)\right]=\left[U_{t c, a}\left(T_{c}-T_{a}\right)+h_{c, p}\left(T_{c}-T_{a}\right)\right]+\tau_{g} \eta_{c} \beta_{c} I(t)(8)
$$

where $\tau_{\mathrm{g}}$ is transmissivity of glass, $\alpha_{\mathrm{c}}$ is absorpitivity of PV module solar cell, $\beta_{\mathrm{C}}$ is packing fraction of PV module solar cell, $I(t)$ is solar intensity, $U_{t c, a}$ is overall heat transfer coefficient, $T_{C}$ is cell temperature, $T_{a}$ is ambient temperature, $h_{c, p}$ is heat transfer coefficient and $\eta_{c}$ is PV module solar cell efficiency.

or,

$$
\tau_{g}\left[\alpha_{c} \beta_{c} I(t)+\left(1-\beta_{c}\right) \alpha_{T} I(t)\right]=\left[U_{L m}\left(T_{c}-T_{a}\right)+\eta_{m} \mathrm{I}(\mathrm{t})\right]
$$

where,

$$
U_{L m}=U_{t, c a}+h_{c p}
$$

and

$$
\begin{gathered}
\eta_{m}=\eta_{c} \tau_{g} \beta_{c} \\
T_{c}-T_{a}=\frac{\left[\tau_{g}\left\{\alpha_{c} \beta_{c}+\left(1-\beta_{c}\right) \alpha_{T}-\eta_{c} \beta_{c}\right\} I(t)\right]}{U_{L m}} \\
T_{c}-T_{\text {ref }}=\left(T_{a}-T_{r e f}\right)+\frac{\left[\tau_{g}\left\{\alpha_{c} \beta_{c}+\left(1-\beta_{c}\right) \alpha_{T}-\eta_{c} \beta_{c}\right\} I(t)\right]}{U_{L m}}
\end{gathered}
$$

with taking $\eta_{\text {ref }}$ is the PV module's electrical efficiency at the reference temperature $\left(T_{r e f}\right)$ and at $1000 \mathrm{~W} / \mathrm{m}^{2}$ solar radiation and $\beta_{\text {ref }}$ is the temperature coefficient of PV module (the values of $\eta_{\text {ref }}$ and $\beta_{\text {ref }}$ can be taken as constant).For the calculation of the electrical efficiency of the PV module (temperature dependent), the expression is used as follows:

$$
\eta_{c}=\eta_{\text {ref }}\left[1-\beta_{\text {ref }}\left(T_{c}-T_{\text {ref }}\right)\right]
$$

$\left[\mathrm{T}_{\mathrm{c}}-\mathrm{T}_{\text {ref }}\right]$ used from Eq. (11) in Eq. (12), temperature dependent electrical efficiency of the PV module will be described as:

$$
\eta_{c}=\eta_{r e f}\left[1-\beta_{\text {ref }}\left\{\left(T_{a}-T_{\text {ref }}\right)+\frac{\left[\tau_{g}\left\{\alpha_{c} \beta_{c}+\left(1-\beta_{c}\right) \alpha_{T}-\eta_{c} \beta_{c}\right\} I(t)\right]}{U_{L m}}\right\}\right]
$$

or, 


$$
\eta_{c}=\frac{\eta_{r e f}\left[1-\beta_{r e f}\left\{\left(T_{a}-T_{r e f}\right)+\frac{\tau_{g}\left\{\alpha_{c} \beta_{c}+\left(1-\beta_{c}\right) \alpha_{T}\right\}}{U_{L m}} I(t)\right\}\right]}{\left[1-\frac{\eta_{r e f} \beta_{r e f} \tau_{g} \beta_{c}}{U_{L m}} I(t)\right]}
$$

ii) Semitransparent PV Module: The semitransparent module can be modeled as follows:

$$
\left[\tau_{g} \alpha_{c} \beta_{c} I(t)\right]=\left[U_{t c, a}\left(T_{c}-T_{a}\right)+h_{c, p}\left(T_{c}-T_{a}\right)\right]+\tau_{g} \eta_{c} \beta_{c} I(t)
$$

or,

$$
\left[\tau_{g} \alpha_{c} \beta_{c} I(t)\right]=\left[\left(U_{t c, a}+h_{c, p}\right)\left(T_{c}-T_{a}\right)\right]+\tau_{g} \eta_{c} \beta_{c} I(t)
$$

or,

$$
\begin{array}{r}
{\left[\tau_{g} \alpha_{c} \beta_{c} I(t)\right]=\left[\left(U_{L m}\left(T_{c}-T_{a}\right)\right]+\eta_{m} I(t)\right.} \\
\text { where, } U_{L m}=U_{t, c a}+h_{c p} \text { and } \eta_{m}=\eta_{c} \tau_{g} \beta_{c}
\end{array}
$$

From Eq.(16)

$$
T_{c}-T_{a}=\frac{\left(\alpha_{c} \tau_{g} \beta_{c}-\eta_{m}\right) I(t)}{U_{L m}}
$$

or,

$$
T_{c}-T_{r e f}=\left(T_{a}-T_{r e f}\right)+\frac{\left(\alpha_{c} \tau_{g} \beta_{c}-\eta_{m}\right) I(t)}{U_{L m}}
$$

With the help of equation (18), Eq. (12)becomes,

$$
\eta_{c}=\eta_{\text {ref }}\left[1-\beta_{\text {ref }}\left\{\left(T_{a}-T_{\text {ref }}\right)+\frac{\left[\tau_{g}\left\{\alpha_{c} \beta_{c}-\eta_{c} \beta_{c}\right\} I(t)\right]}{U_{L m}}\right\}\right]
$$

In opaque PV module solar cell, all the radiation is absorbed by the tedlar and then carried away by the conduction. This increases the temperature of solar cell and its efficiency decreases. But in case of semitransparent PV module maximum radiation is transmitted by glass and its increases efficiency of PV module solar cell.

C. ANN Model:

The analytical model (Electrical or thermal) explained in previous section isexperienced burdensome and time taking process for determining performance parameters. Literature reportsthat an ANN model gives better opportunity to analyst to predict performance parameters.

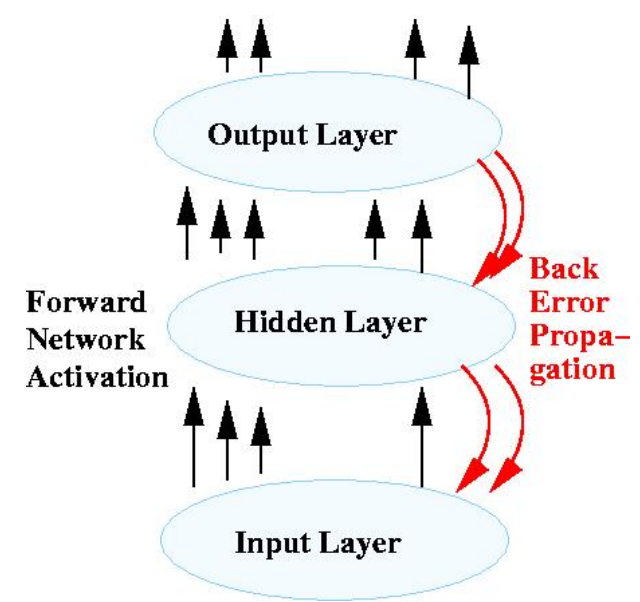

Fig.2: Structure of an ANN model

ANN helps to analyze solar cells located at different places in various weather conditions. The structure of an ANN model is shown in fig.2. The ANN model has three layers as input layer, hidden layer, and output layer. There is two directional propagation of information in the ANN i.e., feed-forward and back error propagation. For ANN model, relation between input and output parameters has been considered as follows:

The input vector $\mathrm{x}=$ [irradiation, cell temperature $]$ is applied to the input layer and net input of hidden unit can be calculated fromequation 20 :

$$
n_{j}^{1}=\sum_{i=1}^{2} w_{j i} x_{i}+b_{j}^{1}
$$

Wherew $\mathrm{w}_{\mathrm{ji}}$ is the weight on the connection from the $\mathrm{i}^{\text {th }}$ input and $\mathrm{b}$ is the bias for hidden layer neurons. Hidden layer output can be calculated from equation 21 :

$$
a_{j}^{1}=f_{1}\left(\sum_{i=1}^{2} w_{j i} x_{i}+b_{j}^{1}\right)
$$


In this way, output of the hidden layer is input to output layer i.e. equation 22:

$$
f_{1}(n)=\tan \operatorname{sig}(n)
$$

andoutput parameters of ANN model can be calculated from equation 23:

$$
a_{k}^{2}=f_{2}\left(\sum_{j=1}^{10} w_{k j} a_{j}^{1}+b_{k}^{2}\right)
$$

Therefore, the ANN model outputs are $a_{k}^{2}$ and it can be considered as $f_{2}(n)$.

\section{Methodology:}

The MATLAB 8 has been used to develop a new algorithm using ANN. The proposed algorithm follows the following steps to achieve performance parameters very close to experimental values of different photovoltaic solar cell under study.

- Initially, the experimental data of semitransparent and opaque photovoltaic thermal module regarding solar irradiation and cell temperature was collected [12].

- An ANN model has been developed and trained for estimation of different electrical parametersusing data set taken from [12].

- Hourly electrical efficiency and cell temperature have been estimated for both PVT modules by analytical and neural network. It has been shown in fig. 4

- $\quad$ Fig.4 shows better result with the semitransparent PVT module.

- Therefore hourly cell temperature effect on cell efficiency for semitransparent PV modules has also been observed and shown in fig.4.Values obtained through ANN model has been compared with analytical model values.

- All performance parameters were also computed for the same input parameters (solar irradiation and cell temperature) for the semitransparentPVT moduleanalytical model.

- $\quad$ RMSE between results obtained from ANN and analytical models of PV solar cell in steps b and c, respectively has been calculated.

- If results obtained from ANN model (step b) differed those of analytical model then a new algorithm was developed in which neural network was again trained on the basis of RMSE for the same input parameters by using back propagation algorithm. The process was continued until getting desired value.

- If output of ANN is accumulated with analytical model then semitransparentPVT module performance parameters can be predicted accurately.

- The schematic diagram of the proposed algorithm is shown in Fig. 3.

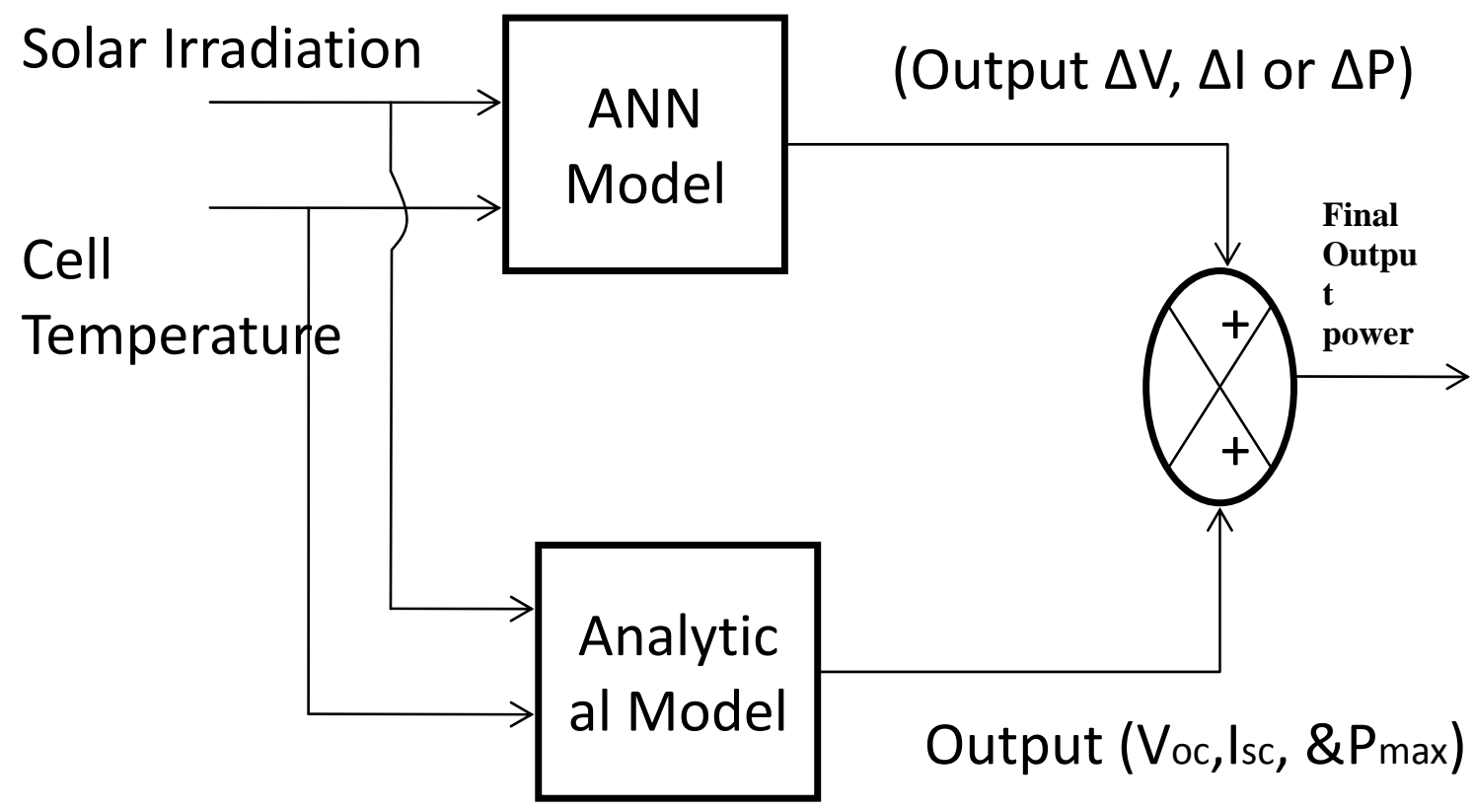

Fig.3:Block diagram of proposed algorithm 


\section{RESUlTS AND Discussion}

In this paper, an effort has been done to develop an algorithm using ANN approach for prediction of performance parameters of different PVT module i.e. G-G (semitransparent) photovoltaic solar cell and opaque PVT module model. Initiallyin this research, artificial neural network with different hidden layers has been used to estimate the different PVT module electrical efficiency with minimum root mean square error (RMSE) which is found less than $2 \%$ which can be ignored.

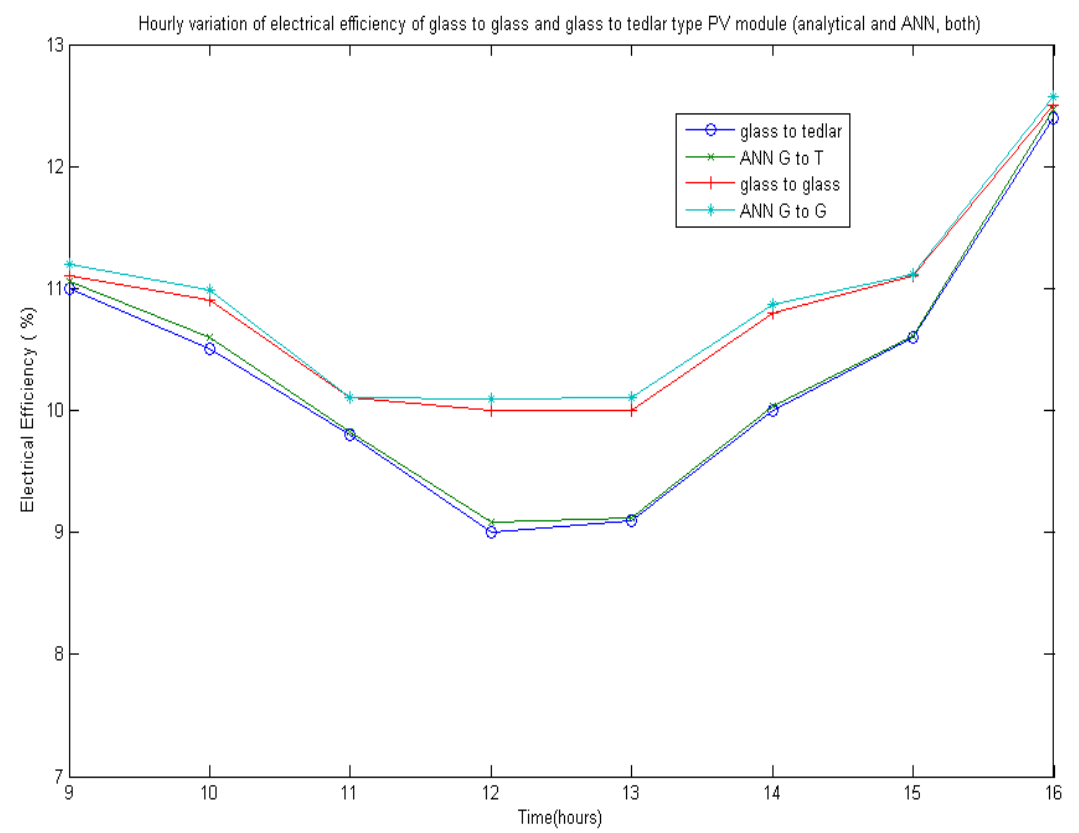

Fig.4: Hourly electrical efficiency estimation from analytical and neural network for both PV modules

The performance of opaque (glass to tedlar) PV module has also been compared with semitransparent (Glass to Glass) PV module in terms of electrical energy output and efficiency and it shows semitransparent (Glass to Glass) PV module performance is better than opaque (glass to tedlar) PV module. Hourly electrical efficiency has been shown in fig.4 for both PV modules i.e. glass to tedlar and glass to glass by analytical and neural network. It shows close relation between analytical and neural network values. Hourly electrical efficiency has been observed for both PV modules i.e. glass to tedlar and glass to glass by analytical and neural network. It shows close relation between analytical and neural network values. It also shows semitransparent PVT module is better than opaque PVT module.

Cell temperature of semitransparent PV module (solar cell) with respect to cell efficiency has also been observed and shown in fig.5. It shows that increase in PV module (solar cell) temperature decreases solar cell efficiency and vice-versa.PV module efficiency has proportional relation with output power. Therefore, maximum output power can be achieved with minimum cell temperature and maximum cell efficiency. 


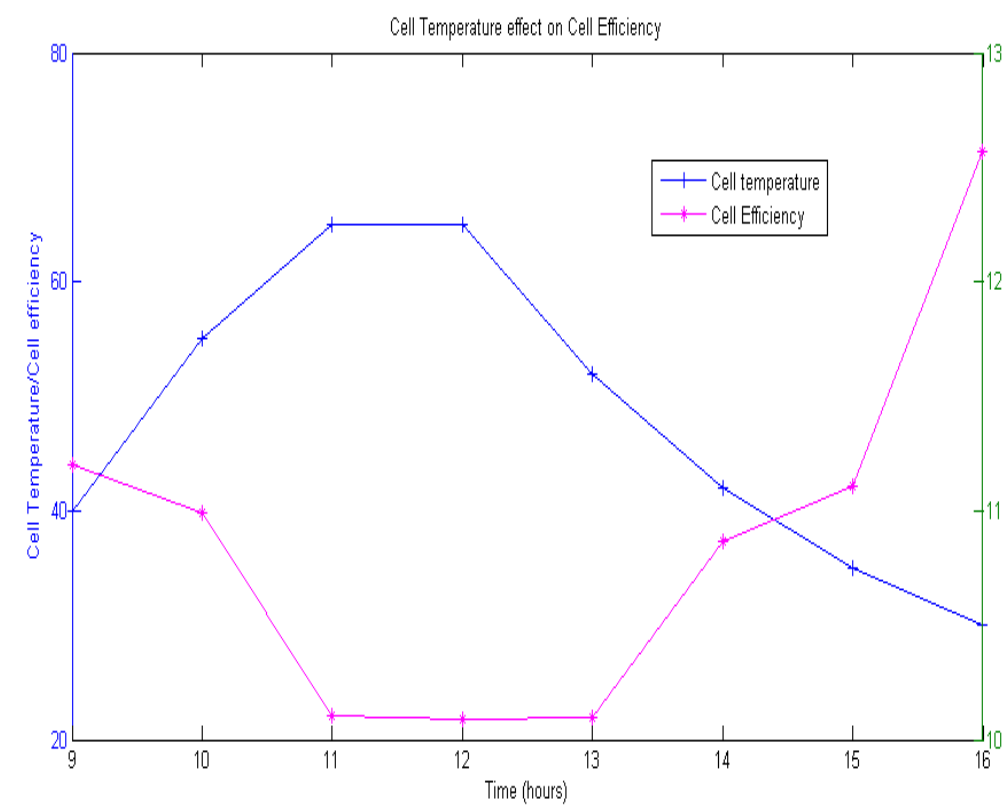

Fig.5: Effect of solar cell temperature on efficiency of Glass-Glass (semitransparent) PV modules

Semitransparent PVT module I-V characteristics of ANN model and analytical model were obtained and output power was also estimated using $\mathrm{I}_{\max }$ and $\mathrm{V}_{\max }$. Fig.6 shows fair agreement between ANN model and analytical model. But, ANN model could not be considered to provide accurate experimental performance parameters i. e. $\mathrm{P}_{\max }$. Authors attempted to calculate RMSE between ANN and analytical models. The RMSE can be calculated using following expression.

$$
e=\left[\sqrt{\frac{\sum e_{i}^{2}}{n}}\right] x 100 \text { Where }, e_{i}=\left[\frac{X_{i}-Y_{i}}{X_{i}}\right]
$$

The RMSE has been calculated $1.6-2.9 \%$ between performance parameter results obtained from ANNand analytical models. The RMSE of $1.6-2.9 \%$ is quite high and therefore, ANN model without takingRMSE into account can't be accepted for results prediction accurately and precisely. This motivated theauthors to develop a novel algorithm by modifying the existing ANN model by taking RMSE intoaccount. The RMSE has been reduced up to $100 \%$ by using proposed algorithm as shown in fig.6. The performance parameters obtained by proposed algorithm are againcompared with analytical values as shown in fig.5. It shows performanceparameters obtained by the proposed algorithm are very much close to experimental values. Theproposed algorithm is found to predict the performance parameters more precisely and accurately thanexisting ANN model available in the literature.

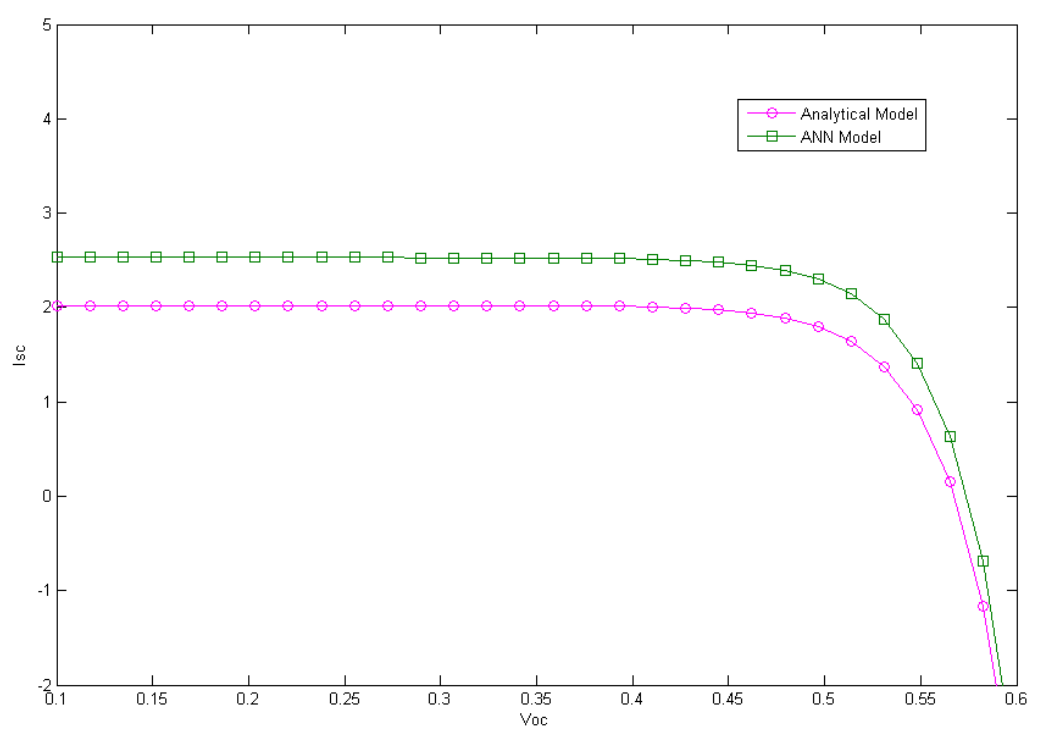

Fig. 6: The comparison of Analytical Model and ANN model 


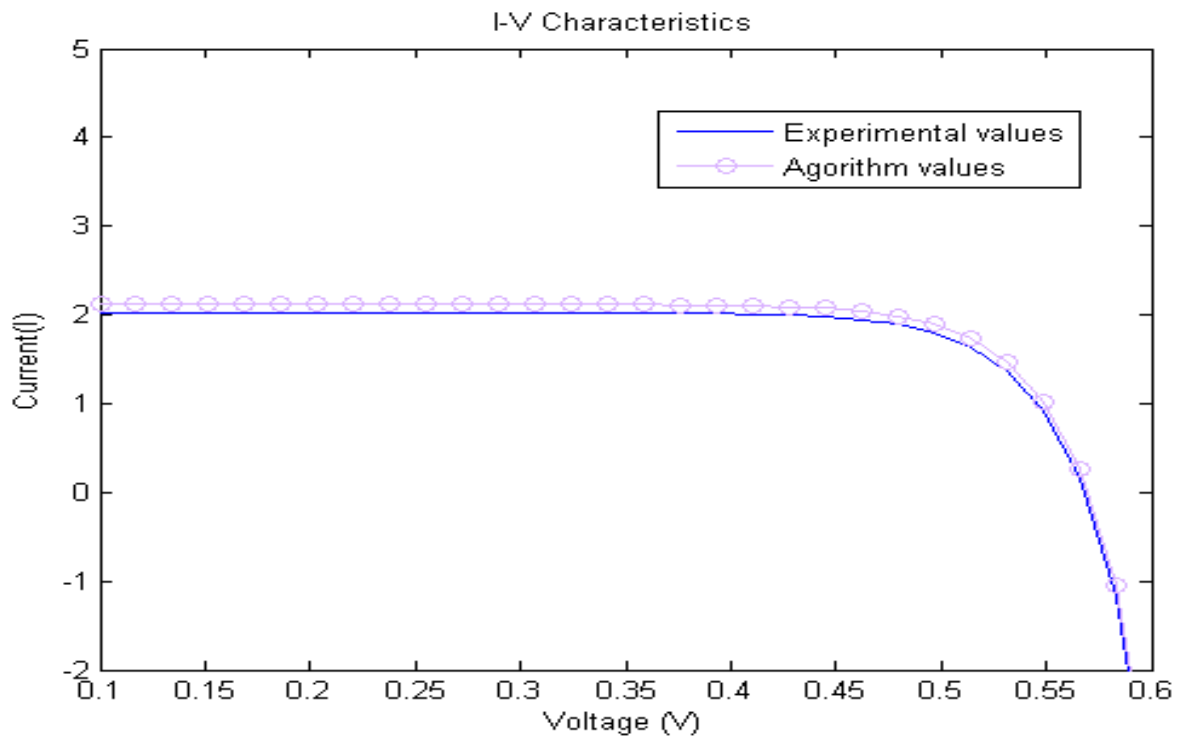

Fig.7: comparison between proposedalgorithm values andExperimental values

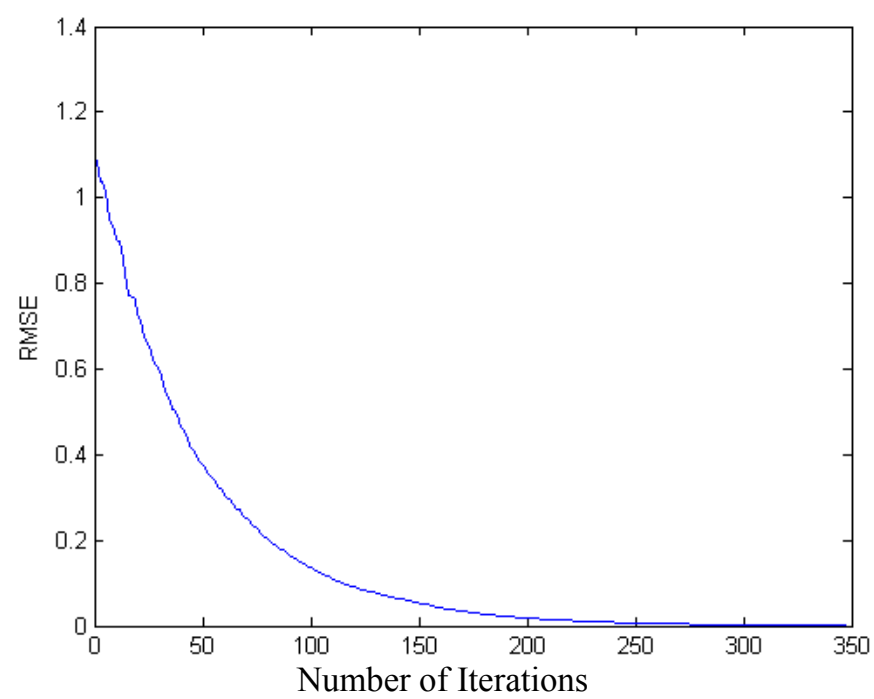

Fig.8: Root mean square error minimizationwith number of iterations in analytical model

\section{CONCLUSIONS}

In this paper, the opaque PV module has been compared with semitransparent PV module in terms of electrical power output and efficiency. It shows semitransparent PV module performance has improved result than opaque PV module. A novel algorithm has also been developed and presented which can minimize the RMSEbetween experimental values and existed ANN model upto100\%. The proposed algorithm can predict the performance parameters i.e. $\mathrm{V}_{\mathrm{OC}}, \mathrm{I}_{\mathrm{SC}}$, and $\mathrm{P}_{\max }$ of a G-G (semitransparent) photovoltaic solar cell very close to experimental values with high accuracy and precision.

\section{REFERENCES}

[1] A. Koca, H.F. Oztop, Y. Varoland G.O. Koca, "Estimation of solar radiation using artificial neural networks with different input parameters for Mediterranean region of Anatolia in Turkey,"Expert Syst. Appl., vol. 38, no. 7, pp. 8756-8762, 2011.

[2] D.L. King, W.E.Boyson, J.A. Kratochvil, Photovoltaic array performance model, Sandia Report No. SAND2004- 3535 available from US Department of Commerce, National Technical Information Service, 5285 Port Royal Rd, Springfield, VA 22161, 2004.

[3] D.L. King, Sandia's PV Module Electrical Performance Model (Version, 2000). Sandia National Laboratories, Albuquerque, NM, September 5, 2000.

[4] E. Ekonomou, "Greek long-term energy consumption prediction using artificial neural networks,"Energy, 2010. vol. 35, pp. $512-517$.

[5] G.K.F. Tso, and K.K.W., Yau, "Predicting electricity energy consumption: A comparison of regression analysis, decision tree and neural networks,"Energy, vol. 32,no. 9, pp. 1761-1768, 2007,.

[6] S.A. Kalogirou, and M., Bojic, "Artificial neural networks for the prediction of the energy consumption of a passive solar buildings,"Energy, vol. 25,pp. 479-491, 2000.

[7] Y., Yoru, T.H. Karakoc, and A. Hepbasli, "Application of Artificial Neural Network (ANN) Method to Energy Analysis of Thermodynamic Systems,"Proc. $8^{\text {th }}$ Int. Conf. on Machine Learning and Applications, Miami Beach,pp. 13-15, 2009.

[8] H. Xie, L. Liu,M. Fei, and H. Fan, "Performance Prediction of Solar Collectors Using Artificial Neural Networks,"Proc. Int. Conf. on Artificial Intelligence and Computational Intelligence,Shanghai, vol. 2,pp. 573-576, 2009. 
[9] W. De Soto, Improvement and validation of a model for photovoltaic array performance. M.Sc. thesis,University of WisconsinMadison,pp.20-74, 2004.

[10] H.N.Singh, and G.N.Tiwari, "Evaluation of Cloudiness, Haziness Factor for Composite Climate,"Energy,vol. 30, pp. 1589-1601, 2005.

[11] D. Kamthania, S. Nayak, and G.N.Tiwari,"Energy and exergy analysis of a hybrid photovoltaic thermal double pass air collector,"Energy Building, vol.43,no.9,pp. 2274-2281, 2011.

[12] D. Kamthania, and G.N.Tiwari,"Performance Analysis of a Hybrid Photovoltaic Thermal Double Pass Air Collector using ANN,"Applied Solar Energy,vol. 48, no. 3, pp. 186-192, 2012.

[13] R. Raja, L.Udhaya Kumar, S.Rakesh Kumar, "Fuzzy logic controller for Photovoltaic array simulator," International Journal of Engineering and Technolgy, vol.5, no.2, pp. 1625-1630, 2013.

[14] S. Singh, S.Agarwal,G.N.Tiwari,, and D.Chauhan, "Application of genetic algorithm with multi-objective function to improve the efficiency of glazed photovoltaic thermal system for New Delhi(India) climatic condition,"Solar Energy,vol. 117, pp. 153-166, 2015.

[15] Shyam, G.N.Tiwari, I.M. Al-Helal, "Analytical expression of temperature dependent electrical efficiency of N-PVT water collectors connected in series,"Solar Energy,vol. 114, pp. 61-76, 2015.

[16] H. Shaker, H.Zareipour, D.Wood, "Estimating Power Generation of Invisible solar Sites Using Publicly Available Data,"IEEE Transactions on Smart Grid,vol. 7, Issue-5, pp. 2456-2465, 2016.

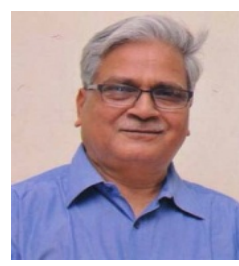

About the authors:

Prof. G.N. Tiwari completed his M.Sc. (Physics) and Ph.D in 1972 and 1976 from Banaras Hindu University, Varanasi (U.P.), India. He is holding a position of Professor at Centre of Energy Studies, I.I.T. Delhi, New Delhi since 1997. He is recipient of National Hari Om Ashram Prerit S.S. Bhatnagar Award in 1982 for his seminal contribution in the field of solar distillation. Dr. Tiwari has published to his credit more than four hundred research papers in different National and International Journals. His current areas of research interest are Solar Energy and its applications in solar distillation, passive heating/cooling of building etc.

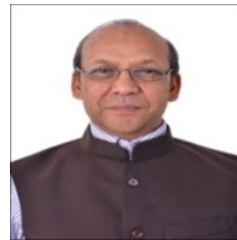

Prof. H.O. Gupta is Director,JIIT, sector 128,Noida.He obtained his B.E. in Electrical Engineering from the Government Engineering College, Jabalpur securing 1st position in Jabalpur University. He received his ME in Systems Engineering and Operations Research and Ph.D. from Indian Institute of Technology, Roorkee in 1975 and 1980, respectively. His research interests are in the area of computer-aided design, reliability engineering, power network optimization, distribution system automation, power quality, power \& distribution transformers and DBMS.

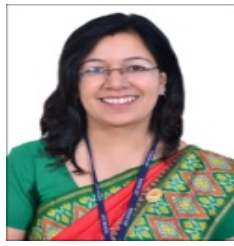

Ms. Ruby Beniwal is Assistant Professor in ECE deptt. ,JIIT, Noida and pursuing PhD from Jaypee University, Noida. She obtained her M.Tech. degree from IIT Roorkee. Her research interests are fuzzy logic and neural network applications and solar energy. 